\title{
MostrEmCasa: Arte, Tecnologia e Experiência Decolonial no Contexto de Pandemia
}

\author{
ShowAtHome: Art, Technology and Decolonial Experience \\ in the Pandemic Context
}

\author{
Claudio Xavier ${ }^{\mathrm{a}, *}$ \\ Kátia Santos de Morais a \\ Nadia Virginia Barbosa Carneiro a
}

RESUMO: O trabalho trata diretamente da experiência na realização de um curso livre na modalidade online, como atividade complementar ao currículo em um curso de graduação na área de Comunicação da Universidade do Estado da Bahia (UNEB). Tal atividade surge como possibilidade em contribuir na construção de rumos/direcionamentos para a educação no contexto da pandemia Covid-19, na medida em que reflexiona o locus de ensino/aprendizagem - processos, espaços, sujeitos - através da arte e tecnologia, a partir de uma perspectiva decolonial. O curso MostrEmCasa teve como objetivo refletir sobre a importância da arte e das linguagens midiáticas como um elemento fundamental para a consciência, acolhimento e enfrentamento aos desafios vividos mundialmente, buscando experienciá-las no cotidiano "mínimo" imposto por esse período de isolamento/confinamento social. Os resultados apontam que a arte, através das tecnologias digitais, numa perspectiva decolonial, se constitui como um recurso para o livre pensar/fazer sobre si e sobre o mundo.

Palavras-chave: Pandemia; Arte; Tecnologia; Ensino/aprendizagem; Experiência Decolonial.

ABSTRACT: The work deals directly with the experience in conducting an open course in the online modality, as a complementary activity to the curriculum in an undergraduate course in the field of Communication at the University of the State of Bahia (Uneb). This activity appears as a possibility to contribute to the construction of courses/directions for education in the context of the Covid-19 pandemic, as it reflects the teaching/learning locus- processes, spaces, subjects- through art and technology from a decolonial perspective. The course ShowAtHome (MostrEmCasa) aimed to reflect on the importance of art and media languages as a fundamental element for awareness, acceptance and facing the challenges lived worldwide, seeking to experience them in the "minimum" daily life imposed by this period of social isolation/confinement. The results show that art, through digital technologies, from a decolonial perspective, constitutes a resource for free thinking/doing about oneself and about the world.

Keywords: Pandemic; Art; Technology; Teaching/Learning; Decolonial Experience.

\footnotetext{
a Departamento de Ciências Humanas, Universidade do Estado da Bahia, Salvador, BA, Brasil.
}

*Correspondência para/Correspondence to: Claudio Xavier. E-mail: rcxavier@uneb.br.

Recebido em/Received: 28/06/2021; Aprovado em/Approved: 01/10/2021.

Artigo publicado em acesso aberto sob licença CC BY 4.0 Internacional ()(i) 


\section{INTRODUÇÃO}

A Universidade do Estado da Bahia(UNEB) é pioneira nacional na adoção do sistema de cotas (juntamente com a Universidade Estadual do Rio de Janeiro-UERJ), em decorrência da reserva de vagas para candidatos negros em universidades públicas; mas também em decorrência da Lei Federal $n^{\circ} 10.639 / 2003$ e, posteriormente, da Lei $11.645 / 2008$, entendendo que essas medidas contribuem enquanto possibilidade de reparação social de grupos subalternizados e destituídos dos espaços de poder, através dos espaços do saber - consequentemente do Ser - como resultado de uma sociedade capitalista, colonialista e colonizadora (Escobar 2005; Lander 2005). Sendo a Bahia, sobretudo a cidade do Salvador, de população predominantemente negra, os espaços do saber nunca tiveram representatividade - gestores, docentes, discentes de grupos minoritários, embora essa condição sócio-histórica seja uma discussão antiga no Brasil. Como efeito das políticas de cotas, uma discussão ampla e complexa se abre e põe em questão a importância de políticas públicas para a construção não somente do acesso, mas da efetivação da representatividade e da permanência de minorias nos loci de produção do conhecimento (Queiroz 2000; 2002; Mattos 2007) ${ }^{1}$.

No cenário da pandemia COVID-19, deflagrada no início do ano de 2020 (OMS 2020), nos deparamos com uma série de desafios relacionados ao convívio em coletividade e às interações sociais, especialmente aquelas que acontecem no contexto da educação e das relações de ensino/aprendizagem e que, historicamente, têm sido pautadas em processos que se dão nos espaços formais (mas não só). Esses desafios vêm sendo acompanhados de discussões nas diversas instâncias da sociedade civil do Brasil e do mundo (Fidalgo 2020; Santos 2020) e as orientações apresentadas por autoridades da saúde e sanitárias, a exemplo da Organização Mundial da Saúde (OMS), têm direcionado para a suspensão de atividades coletivas em espaços que levem à aglomeração de pessoas, sendo o Brasil, o país com escolas fechadas por mais tempo durante a pandemia (UNICEF, WHO, and IFRC 2020; OCDE 2020).

Essas discussões no Brasil são ambivalentes, na medida em que não produzem um consenso sobre a adoção de medidas preventivas e de solução para os impactos causados pelos efeitos e riscos advindos da pandemia - desde a contaminação pelo vírus à perda ou inexistência de fluxos geradores de bens materiais e simbólicos e de capital tangencial, conhecimento e (in)formação, a partir do que se produz em escolas e universidades (Ribeiro 2021; 2020). Contudo, elas se constituem em um locus para reflexão e reflexividade de professores e pesquisadores ao questionarem qual o papel da educação, das universidades e do ensino/aprendizagem frente aos desafios e impactos impostos pela pandemia.

Falas convergentes e divergentes em torno de uma reflexão e busca por soluções quanto ao cenário da educação nesse contexto apresentam, de uma forma geral, tentativas em responder: como a educação - em seus diversos níveis - pode contribuir na construção da consciência sobre o atual cenário e seus impactos na vida em sociedade? Qual o papel de professores e pesquisadores frente às diferenças e desigualdades de estudantes e o (não)acesso à educação em tempos de descorporificação? E, mais especificamente a partir da nossa experiência, de que forma

\footnotetext{
${ }^{1}$ Além do Sistema de cotas sociorraciais, em 2019 a Universidade do Estado da Bahia-UNEB, instituiu o programa de cotas para transexuais, travestis, quilombolas, ciganos, pessoas com deficiência, autismo e altas habilidades.
} 
a arte e a tecnologia podem tocar a dimensão do sensível no atual cenário, considerando a realidade de minorias subalternizadas?

Diante desses e outros questionamentos sobre o papel da universidade pública e de um curso na área de Comunicação, assim como o lugar de professoras/pesquisadoras e professores/pesquisadores na ausência da sua razão - o locus, sala de aula e estudantes; bem como espaço e condições para a pesquisa - nos reunimos online para refletir, debater e propor alguma alternativa, buscando contemplar a dimensão do acolhimento em um coletivo (docentes/discentes) frente esta realidade que se apresenta assustadora e que demanda por estratégias que pensem (sobre)viver no hoje para o amanhã.

\section{DE REPENTE, O ENSINO REMOTO}

Há pouco mais de um ano, de uma hora para outra, tivemos que passar a nos comunicar mediados por uma tela. As aulas, a partir daquele momento, se dariam de forma remota. O contexto era novo, o cenário era novo e no meio disso um sentimento sem nome, um abismo feito de silêncios aumentando a distância entre nós (docentes e discentes), uma vez que não tínhamos mais a visibilidade total do olho no olho, do gesto, das expressões faciais, da dúvida ou da discordância. Uma descorporificação (Marotta 2017). De repente, somos forçados a um aprendizado extra, a intuir no coração o que os olhos não podem mais ver.

Como parte dessa nova relação mediada, pela metade, partida, fragmentada, fomos instados a redobrar nossa atuação, como que para compensar a falta da performance do nosso corpo se movendo, materializado no espaço, e trocando sinais verbais e não verbais pela sala de aula na intencionalidade da comunicação com e para todos/todas.

Com o ensino remoto, estamos sempre "do lado de cá" de algum lugar que mais se parece uma ilha e, a turma/alunos, "do lado de lá" localizados em algum ponto do grande arquipélago etéreo que se tornou a antiga sala de aula. Essa perspectiva, imprecisa, inapreensível, não apenas muda a forma como nos relacionamos, mas, sobretudo, mexe profundamente com o grau de intimidade e de troca, tal como conhecíamos.

Mas o que, de fato, aprendemos até aqui dessa experiência? Quais os ganhos e os prejuízos? Como fica a nossa relação de confiança entre professores(as) e estudantes? Como isso afeta a nossa saúde física e mental? De um momento para o outro, fomos apartados uns dos outros e, recém instalados em nossas solidões de ilhas, sentimos aprofundar, pouco a pouco, o abismo criado pelo contexto pandêmico. Mas, como lidar com as dificuldades materiais do ensino remoto? Como adaptar os programas? Como falar? Como ouvir? Como avaliar? Como sentir e compreender o que os olhos não veem, o que o ouvido não ouve e o gesto ou expressão facial não pode mais mostrar?

Assim, nasceu a proposta MostrEmCasa: arte, registros do cotidiano e perspectivas para o futuro, oferecida como curso livre na modalidade de mediação tecnológica, totalmente online, realizada em uma plataforma de comunicação de uso institucional. O objetivo do curso foi refletir sobre a importância da arte e das linguagens midiáticas como um elemento fundamental para a consciência, acolhimento e enfrentamento aos desafios vividos mundialmente, buscando experienciá-las no cotidiano "mínimo" imposto por esse período de isolamento/confinamento social. 
A proposta do MostrEmCasa encontra-se fundamentada no conhecimento e na formação das professoras e pesquisadoras e do professor e pesquisador, autores deste trabalho, atravessados pela arte e pela tecnologia, compreendendo a importância da experiência estética e do fazer com os dispositivos multifunções, móveis e geo-referenciados, e que fazem parte do cotidiano. Há, ainda, a compreensão de que esses dispositivos funcionam acoplados ao corpo do sujeito na sociedade contemporânea (Vicini and Brazal 2015) o que pressupõe um pensar sobre a importância em provocar e propor conexões com o sensível, como possibilidade de (re)apropriação desses dispositivos, suas formas e lógicas socialmente instituídas.

\section{As tecnologias como tradução da nossa sensibilidade}

A natureza da sensibilidade - e a relação com a natureza - tem sido distanciada dos percursos e itinerâncias (in)formativos nos diversos currículos, dada a condição epistemológica ainda dominante, de separação sujeito-objeto. Tem-se, portanto, uma representação hegemônica que impacta diretamente na produção do conhecimento e no papel das universidades diante das dicotomias entre "alta cultura - cultura popular; educação - trabalho; teoria - prática" sobretudo a partir de epistemologias dominantes (Santos 2001; Meneses and Santos 2009; Fróes Burnham 2000). O peso da racionalidade lógica e do conhecimento discursivo tem sido imposto tal qual demanda de mercado, cujos valores atribuídos ao pensamento precisam atender a um esquema de interesses entre oferta e consumo (Beck, Giddens, and Lasch 1995).

Como consequência, o conhecimento sobre a informação - a partir da literatura de Daniel Bell a Manuel Castells, no contexto da sociedade da informação - tem sido considerado como o processamento da informação (Lash 2005). A busca/uso desse conhecimento, nomeadamente, das tecnologias digitais de informação e comunicação, torna-se, por assim dizer, de cunho salvacionista, ao apostar nas tecnologias do virtual como a grande "terra prometida" (Wertheim 2001).

Atrelado a isso, as políticas de desinvestimento na formação humana, em nome do modelo neoliberal financista, negam a possibilidade de exercício da alteridade e de uma participação protagonista e emancipadora de sujeitos nas relações consigo e com o outro e nos processos político-sociais. A relação com o mundo e com o outro, distante do sensível, dá margem à construção de projetos político-pedagógicos egoisticamente pragmáticos, despreocupados com a reflexividade e a transformação (Morin 1993).

A arte é uma expressão e ao mesmo tempo um processo de produção do humano que, desde os primórdios, também contribui para a compreensão da história social do conhecimento, tendo em vista não somente as diversas formas sócioculturalmente instituídas (Burke 2003). Além de racionalmente quantificar, especificar, classificar, organizar, sistematizar e indexar, a arte busca não simplesmente "descobrir o segredo do mundo em uma palavra-chave", mas "dialogar com o mistério do mundo" (Morin 1993). É, portanto, possibilidade direta de estar no mundo e relacionarse com o mundo, através da sensibilidade.

A relação arte e tecnologia é ontológica e faz parte da construção do humano, como algo que se expressa na linguagem/cultura e nas atividades cotidianas como um jogo arte e jogo têm um livre e desinteressado ir e vir (Gadamer 1997). O fazer artístico com as tecnologias digitais de informação e comunicação possibilitam articulações com as 
diversas áreas do conhecimento, através da cultura das redes (Lévy 1999). O desenvolvimento das tecnologias e da própria arte tem se dado como um processo de conhecimento em que ambas se entrecruzam subsidiando saberes alimentados pela cultura das redes e da participação (Jenkins 2008).

A ideia de arte; de tecnologia; e de arte e tecnologia - inacessíveis às minorias subalternizadas, apartadas de suas subjetividades e distantes de suas realidades - não se constituem senão agenciamento para o contínuo exercício colonizador. O acesso a dispositivos móveis e às redes de comunicação tem sido útil ao sistema que controla e utiliza dados pessoais através de algoritmos. Teatros, museus e galerias têm se tornado representantes de uma cultura predominantemente privilegiada por índices e marcadores sócio-históricos que dividem classe, raça e gênero.

Uma outra ideia de arte e tecnologia, enquanto acesso e uso, torna-se necessária. Isto nos leva a crer na possibilidade de subversão dos meios e das linguagens dominantes, para dar vazão à sensibilidade e à subjetividade. Arte e tecnologia, numa perspectiva decolonial, podem subverter o pensamento hegemônico e instituído sobre arte e sobre tecnologia. Neste sentido, 'decolonizar', se pudermos verbalizar o conceito, não é apenas romper com o instituído, mas, inventar um fazer que inaugura passagens, acessos e percursos pela via da sensibilidade. Ou seja, a estética move a subjetividade para uma escolha ética não mais baseada em padrões institucionalizados, cânones ou sistemas pré-definidos.

Em tempos pandêmicos, cujo horizonte apresenta incertezas, fragilidades, medos e uma sorte de outros sentimentos, a arte e as tecnologias de informação e comunicação se apresentam como promotora do sensível, através da experiência direta com o fenômeno (Bronowski 1983). O caminho do sensível e, por conseguinte, da subjetividade humana, é um "para além" daquilo que se torna padrão de formas dominantes e homogeneizantes de Ser.

Considerando o cenário pandêmico instaurado em 2020, urge refletir sobre alternativas que contemplem a permanência de minorias subalternizadas em espaços do saber, tendo em vista que as condições de desigualdades por que vivem essas minorias - de moradia, acesso e uso de tecnologias e redes de comunicação - colocamnas em um nível de exposição e vulnerabilidades infinitamente maiores, não somente em relação ao vírus SARS-COV-2 (da COVID-19), mas em relação ao desemprego, subnutrição, ansiedade, depressão e outras doenças mentais, que não somente interferem na relação ensino-aprendizagem mas que podem conduzir à falta de estímulo e desistência da universidade enquanto possibilidade de transformação da realidade social através do conhecimento.

Sendo a Universidade do Estado da Bahia-UNEB, uma Universidade preta, periférica e inclusiva, socialmente referenciada, a preocupação com o público de estudantes no atual cenário pandêmico procurou contemplar as dimensões da diversidade e da diferença que lhe constitui, através de uma proposta metodológica que permitisse a livre expressão como possibilidade de enfrentamento à cultura dominante e ao pensamento colonialista e colonizador. 


\section{METODOLOGIA/RESULTADOS: QUANDO O ÊXITO RESULTA DE UM FAZER LIVRE}

A proposta do curso livre MostrEmCasa foi estimular estudantes a uma elaboração/reelaboração das sensações individuais e coletivas provocadas ou aprofundadas como efeito da pandemia Covid 19 e a uma materialização deste processo através da relação arte-tecnologia. A busca foi por uma experiência formativa capaz de acionar os caminhos do sensível em contato, de maneira livre, com conteúdos inerentes à formação acadêmica de estudantes participantes a partir de suas vivências cotidianas.

O isolamento social neste caso foi entendido como possibilidade para exercício de uma criação artística autônoma e consciente. Com isso, o curso propunha uma perspectiva de formação assentada no acolhimento entendido como necessário em meio a um cenário de paralisação total das atividades presenciais acadêmicas em função das restrições impostas pelo vírus a todo o mundo.

Há nessa compreensão uma dimensão política. Quando falamos em uma (re)elaboração do conhecimento estamos considerando sobretudo a interseccionalidade (Akotirene 2019) para a análise do perfil de participantes e os contextos sociais experienciados, com ênfase no período de quarentena. De quinze participantes do curso - estudantes do curso de Relações Públicas da Universidade do Estado da Bahia - quatorze estudantes são mulheres. A maioria, jovens; negras e de baixa renda.

O curso livre foi desenvolvido através de encontros semanais online com duração de 1 hora e uma carga horária total de 20 horas. A atividade foi registrada no Sistema Integrado de Projetos de pesquisa e extensão da Universidade e, nesse sentido, possibilitou a certificação da carga horária como aproveitamento curricular (ACC).

Como expectativa de resultado final do curso, a proposta apresentada a estudantes foi a de desenvolverem um produto individual ou coletivo conciliando as linguagens artística e comunicacional - poesia falada, fotografia, vídeo, dramaturgia (podcast), etc - e com difusão online. A condição colocada foi que os produtos fossem desenvolvidos no contexto do espaço físico de cada participante, fazendo-se refletir no resultado das produções - em respeito às normas sanitárias de distanciamento e isolamento social - inclusive para quem optasse por projetos não individuais. Nestes casos, toda a interação e trocas necessárias à execução do projeto deveriam ocorrer à distância (através de mediação tecnológica), de acordo com as orientações e decretos da Organização Mundial da Saúde-OMS e órgãos representativos do Governo local, nomeadamente, Secretaria da Educação do Estado da Bahia (SEC) e Secretaria da Saúde do Estado da Bahia (SESAB).

Do ponto de vista metodológico, uma abordagem muito importante que adotamos foram os chamados "momentos de escuta". Neles, estudantes tinham a oportunidade de evidenciar suas demandas e questões relacionadas com o contexto de confinamento. Esses momentos permearam uma organização de trabalho que contemplou aulas expositivas seguidas de discussão e encontros de orientação individual e coletiva.

A orientação de um fazer que unia conhecimento e invenção, improviso e superação, medo e ousadia, só poderia se dar com total delicadeza, escuta, incentivo e doses de 
exemplos de artistas e obras que experimentaram mais ou menos tal contexto. $\mathrm{O}$ tempo de cada um e de cada uma também foi respeitado e, ao mesmo tempo acompanhado, uma vez que, mesmo a arte, sofre pressões de fora que colaboram para seu êxito. Em um mundo ideal perfeito, provavelmente, a arte não encontraria motivação. Toda obra nasce de um desconforto, de um ponto antes de uma virada de perspectiva. A tensão fazia e faz parte do processo, como se pode ver nos relatos de participantes do curso.

Os quatro primeiros encontros foram assim distribuídos: 1) apresentação: escuta de si, em que foi possível apresentar a proposta, construir acordos didáticos e, sobretudo, escutar estudantes sobre o contexto de cada um/uma em relação à pandemia (Barbier, 1998); 2) aqui e agora: meu lugar de fala, cujo objetivo foi sensibilizar estudantes quanto à necessidade de olhar para dentro (de suas casas e de si) através de registros fotográficos e desenhos; 3 ) a arte de fazer arte em tempos estranhos, em que a reflexão sobre o fazer artístico e a experiência estética surgem como possibilidade de pensar o fazer; e 4) arte e mídias: horizontes na e para além da pandemia, cuja proposta foi apresentar e discutir o processo de criação artística em linguagens diversas da comunicação no cenário de isolamento social no sentido de uma reflexão sobre a arte como um movimento de negociação, resistência e experimentação em meio ao caos, respeitando as vivências e experiências individuais. Outros encontros aconteceram na sequência, para fins de orientação individual e coletiva e acompanhamento dos projetos.

No encontro cujo tema foi aqui e agora: meu lugar de fala, selecionamos o texto "na Europa a casa do homem ruíu", depoimento/reflexão de Lina Bo Bardi em relação aos impactos da Grande Guerra na Europa (Rubino and Grinover 2009). O texto permite estabelecer uma conexão com restrições, cerceamentos, destruições e perdas e, através disto, uma sorte de sentimentos que conduzem ao olhar sobre si e à subjetivação construindo um lugar de fala único. Foi proposto, enquanto exercício, a realização individual de uma sequência de fotografias sobre o espaço em que se encontrava cada estudante, a partir do seguinte esquema de registro e representação de objetos para: forte, frágil; belo, feio; alegre, triste (Figura 1). As categorias foram escolhidas a partir de expressões mais utilizadas nos diálogos/falas durante a escuta sensível com estudantes (Barbier 1998).

Figura 1. exemplo de ensaio fotográfico como resultado do exercício.
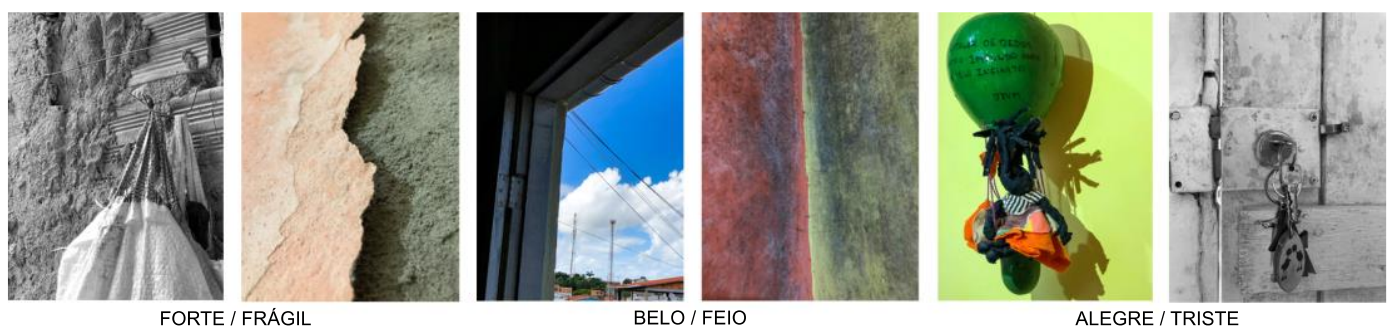

Fonte: produção do curso MostrEmCasa

A obra Os problemas da estética (Pareyson 2001) foi o ponto de partida no encontro $A$ arte de fazer arte em tempos estranhos, especialmente seu passeio pelas definições mais tradicionais de arte ao longo da história do pensamento - arte como fazer, como conhecer e como exprimir - para argumentar que a atividade artística consiste fundamentalmente no formar. Para o filósofo, o êxito, no sentido de a obra ser o que tem de ser, é o parâmetro para defini-la como tal. Toda obra é um fazer, toda obra é 
uma forma de conhecimento, toda obra é também expressão. Mas, segundo Pareyson, a forma, entendida como a invenção de algo que não existia antes, engenho, sentir, trabalho que plasma arte, êxito (Pareyson 2001).

Discutidas questões conceituais importantes aos contornos do curso, o encontro Arte e mídias: horizontes na e para além da pandemia propôs uma reflexão sobre a relação entre arte, mídias e cotidiano a partir de um olhar direto para a realidade naquele momento, considerando algumas experiências iniciais de produção e de adaptação do universo artístico-midiático ao cenário da Covid 19 no Brasil e no mundo. Neste sentido, voltou-se tanto para experiências institucionais (a exemplo da abertura de museus consagrados para visitação online e de iniciativas de universidades no acolhimento à participação popular através de atividades extensionistas interessadas em percepções sobre o período de quarentena) e de coletivos artísticos (como festivais de dança e música tradicionalmente físicos experimentando versões online), até iniciativas individuais e coletivas de uma adaptação possível ao novo cenário (o retorno do cinema drive in, a estreia de monólogos e peças teatrais totalmente online, coletivos artísticos promovendo saraus virtuais, a adaptação das máscaras como objeto artístico, etc.).

Ao enfatizar o expressivo surgimento de projetos e atividades culturais moldados a partir das restrições impostas pela pandemia e tendo a própria pandemia como tema, buscamos provocar estudantes participantes quanto à não negação do vírus e seus reflexos, mas a uma negociação, um acolhimento às sensações decorrentes desta experiência. Assim, discutiu-se o vídeo, o áudio, a fotografia e outras linguagens como possibilidade de escoamento das emoções a partir de processos artísticos individuais e/ou coletivos.

Durante os encontros houve uma preocupação em construir algo metalinguístico falar de experiência com experiência; falar da importância em olhar para dentro, exercitando o olhar interior; falar de imagens com imagens, etc. Dessa forma, falar de arte e tecnologias se constituiu, enquanto proposta de curso, uma metalinguagem possibilitada justamente por essa interseção entre as linguagens artísticas e as várias mídias.

Nessa perspectiva, nós também nos permitimos a um exercício de livre criação como forma de reflexão sobre aquela experiência formativa, utilizando linguagens/tecnologias da comunicação (Figura 2). Tal exercício se colocava como forma de estímulo para que estudantes participantes também se sentissem à vontade para exprimir as suas sensações em meio ao contexto vivenciado. 
Figura 2. Exemplo de exercício de livre criação-interseção arte e mídias.

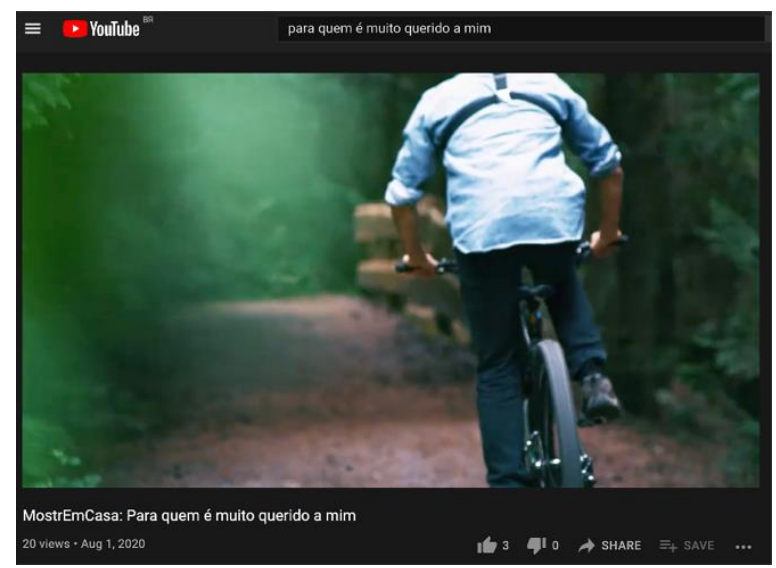

Fonte: YouTube "MostrEmCasa: para quem é muito querido a mim"

A descrição do vídeo acima apresenta:

Este vídeo, originariamente, nasceu como um recado para os participantes do Curso Livre "MostrEmCasa: Arte, registros do cotidiano e perspectivas para o futuro", ministrado pelos colegas professores Claudio Xavier, Katia Morais e eu, para alunos e alunas do Curso de Comunicação Social - Relações Públicas do DCH-I da UNEB. Nele eu abro o meu coração e conto parte da minha história pessoal para mostrar que todos nós temos o direito e devemos deixar nossa marca nesse mundo. Imagens de bicicleta pontuam a fala aludindo a paixão da autora pela sensação de liberdade que pedalar uma "magrela" proporciona. Prazer hoje proibido pelos médicos por conta da artrose grave que limita meus movimentos. (professora Nadia Virginia, autora do vídeo)

Com exceção de um projeto em podcast, a linguagem audiovisual foi a escolhida por estudantes participantes para desenvolvimento dos projetos, considerando o acesso que têm em relação aos dispositivos móveis e estes como artefatos do cotidiano - os diversos recursos e soluções inerentes às plataformas de comunicação na cultura contemporânea são familiares à geração de estudantes. Destacamos a seguir dois dos projetos realizados, Desmedona e Registros de mim, considerando o nível de implicação das respectivas autoras e a narrativa enquanto reflexo de imersão no sensível e no universo interior (Figura 3).

Figura 3. Exemplo dos produtos finais enquanto resultado do curso livre.

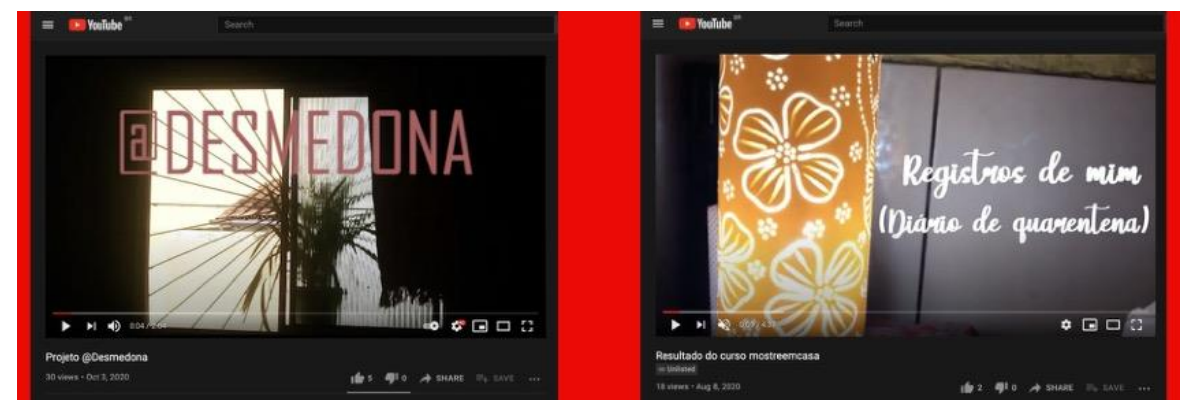

Fonte: Youtube “Desmedona" e "Registros de mim (diário de quarentena)"

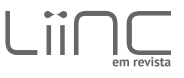


O vídeo 1, Desmedona, enquanto descrição no YouTube, nos possibilita o seguinte depoimento:

Durante a pandemia, ano 2020 eu tive o que talvez seja a pior crise de identidade de todas. No auge dos meus 23 anos eu me vi como uma mulher bipolar em busca de autoconhecimento e eu encontrei ele nas artes, mais especificamente na reforma que fiz no meu quarto, onde através das expressões que fiz nas minhas paredes eu consegui expressar o meu eu sendo várias mulheres, isso é ser Desmedona, o encontro entre todas elas, entre todos os meus (eus). (Autora do vídeo 01)

O vídeo 2, Registros de mim, enquanto descrição no YouTube, apresenta:

Como liberar suas emoções sentidas durante o isolamento social? Uma menina, um celular e a imaginação. Registros de 60 dias escritos no que viria a se transformar em um diário de quarentena. (Autora do vídeo 02)

Os trechos acima dão uma mostra do resultado do curso enquanto proposta de apropriação da arte e das tecnologias para tradução da sensibilidade frente aos desafios vividos durante a pandemia. A ruptura com as experiências sociais cotidianas - sobretudo a ausência do espaço físico universitário - solidão, crise existencial, relacionamento com a família, dificuldades financeiras, negociação com o espaço físico, etc, foram temáticas recorrentes durante os encontros, o que refletiu nos projetos finais.

A interseccionalidade (Akotirene 2019) merece ser ressaltada como um componente fundamental para a compreensão sobre o próprio processo de desenvolvimento do curso. O fato de reunir uma maioria de jovens mulheres negras de baixa renda foi elemento definidor para a experiência do MostrEmCasa, não só no que se refere às produções em si enquanto materialidade final, mas ao processo mútuo de ensino e aprendizagem docente-discente e, como consequência, ao contínuo processo de (re)construção das relações entre o grupo participante. Essa interseccionalidade trouxe à tona pautas, conflitos, dilemas que perpassam este grupo social e que ganharam novas camadas no contexto da pandemia. A constituição de um ambiente formativo de acolhimento tornou possível que as estudantes expusessem as suas vivências segundo seu ponto de vista e que as pautas emergentes dessas atuações de algum modo fossem também acolhidas como objeto de reflexão.

Ainda enquanto proposta do curso livre, sugerimos e discutimos formas de exposição e/ou divulgação do que fora produzido. Neste sentido, pesquisamos sobre editais, chamadas de trabalhos e outros em que a temática central fosse a quarentena em função da pandemia Covid-19. Dentre as diversas iniciativas identificadas, o perfil no Instagram @curtaquarentena foi escolhido como ambiente de difusão das produções geradas a partir do curso MostrEmCasa.

Ao mesmo tempo em que a plataforma se apresentou como um ambiente coletivo de compartilhamento de sensações através da arte, seu caráter não institucionalizado contribuiu para nossa escolha. Era importante, na perspectiva defendida por nós, nos conectarmos a iniciativas protagonizadas por sujeitos imersos no universo artísticocultural não representantes de instituições consolidadas no campo. Há nessa perspectiva uma preocupação com a discussão sobre as relações entre conhecimento e poder (Lander 2005). O Curta Quarentena foi um projeto contemplado em um edital 
de emergência da Secretaria de Cultura do Estado do Rio de Janeiro e funcionou como um concurso audiovisual livre à participação dentro das regras e temática (a quarentena) estabelecidas pelos seus organizadores.

Entendemos que havia ali uma possibilidade de diálogo, de expansão ao trabalho desenvolvido no contexto universitário e de estímulo à participação de estudantes em fóruns reunindo sujeitos interessados em mobilizar recursos da comunicação para acionar a dimensão do sensível. Após finalizados, compartilhados e discutidos internamente no âmbito do MostrEmCasa, os vídeos deveriam ser submetidos ao perfil @curtaquarentena pela própria autoria.

Figura 4. Exemplo de vídeo submetido à seleção/mostra Curta Quarentena.

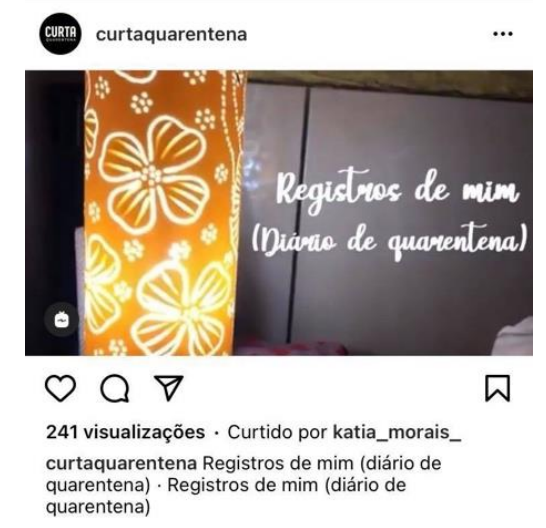

Fonte: Perfil no Instagram @curtaquarentena

Paralelamente, acordamos sobre a criação de um perfil no Instagram como forma de registrar as produções e de servir como mostra - literalmente MostrEmCasa (Figura 5).

Figura 5. Criação do perfil para publicação e mostra das produções.

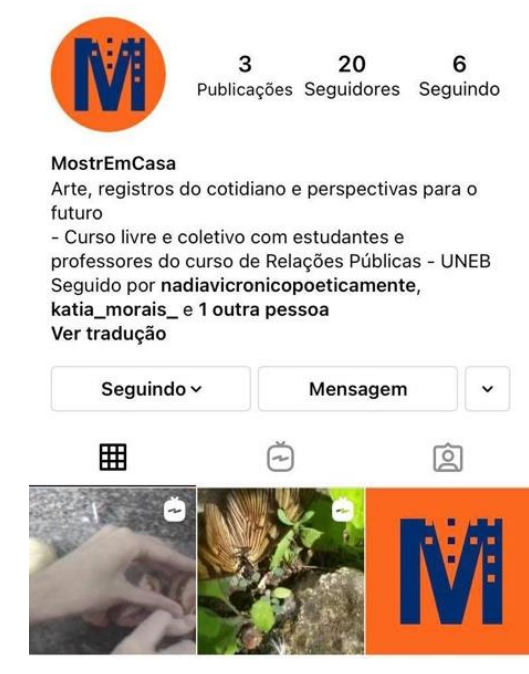

Fonte: Perfil no Instagram @mostremcasa

A criação de um perfil para publicar as produções do MostrEmCasa suscitou a possibilidade de se construir um coletivo protagonizado por estudantes participantes, ampliando-se àqueles que demonstrassem interesse. Nosso entendimento foi que, na medida em que começássemos as postagens no perfil @MostrEmCasa através de 
imagens, textos, hashtags, links; e na medida em que estabelecêssemos parcerias e articulações com outros estudantes, professores, coletivos e colaboradores, além de eventos e ações, já estaríamos, de maneira orgânica, nos apresentando como tal.

A partir de então, a ideia era que estudantes participantes se organizassem e assumissem o coletivo, conduzindo-o segundo sua compreensão sobre aquela iniciativa. Nós professores contribuiríamos na condição de apoiadores. A criação do Coletivo não chegou a ser efetivada. Fatores como o calendário acadêmico atípico com início do recesso letivo e férias logo após o encerramento do curso livre - e consequente desmobilização estudantil foi decisivo. Contudo, considerando a perspectiva de êxito (Pareyson 2001), entendemos que o objetivo foi alcançado. Apenas dois participantes não concluíram o curso ou não desenvolveram uma produção final.

\section{CONSIDERAÇÕES FINAIS}

O curso livre MostrEmCasa foi uma atividade acadêmica complementar constituída como experiência inicial de enfrentamento/negociação ao vírus da Covid-19 e seus efeitos em um momento em que pouco se sabia a respeito da doença e de suas implicações para um possível retorno ao pleno funcionamento das universidades no Brasil. O projeto envolveu duas professoras pesquisadoras e um professor pesquisador que têm histórias formativas perpassadas pelos campos da arte, comunicação e tecnologias com a proposta de um fazer com estas áreas, enquanto possibilidade de acolhimento e de escuta a estudantes do curso de Relações Públicas, considerando os prejuízos à formação decorrentes da ruptura com a vivência universitária.

O acolhimento a experiências individuais se revelou um processo rico em construção de consciência coletiva sobre os efeitos da pandemia na medida em que participantes foram se conectando a impressões e angústias relatadas por colegas. Incluem-se aqui os relatos quanto ao sentimento de ausência da ambiência acadêmica offline e dos processos coletivos decorrentes desta experiência. Nesse aspecto, o desafio em trabalharmos juntxs a partir de uma mediação tecnológica totalmente online, se constituiu em um jogo de faltas e complementações.

As falas livres foram motivadas sempre durante os encontros virtuais e principalmente relacionadas com o contexto pandêmico na perspectiva individual de cada sujeito. Os relatos apresentaram sentimentos associados à distância de alguns familiares e amigos, ausência do convívio social, medo de adoecimento e perdas e do que se apresenta(va) enquanto futuro indefinido, além de outras afetações emocionais. Essas falas e as provocações realizadas com o exercício de olhar para os espaços em que se circunscreviam, através do ensaio fotográfico (Figura 1), produziram experiências de um olhar para dentro de si, enquanto registros do cotidiano e também como possibilidade de transformação do próprio olhar (Bachelard 2000), através de depoimentos como "nunca havia percebido esse objeto assim", e "descobri espaços que não existiam antes".

Os projetos apresentados como resultado final do curso livre trazem uma característica marcante que é a imersão nesses espaços mais íntimos. Principalmente os vídeos, trazem imagens de um fazer cotidiano com atividades domésticas, de lazer, alimentação, cuidados com o corpo e de relação com o próprio espaço, através de intervenções. Isto denota um compromisso não somente com o que foi proposto 
enquanto atividade, mas, também, com o tema de cada produto da atividade. Mais uma vez, Bachelard (2020) nos lembra que a casa, para além de qualquer outra coisa, é o espaço interior, faz parte do que ele chama de valores da intimidade. A casa, segundo Bachelard (2020) é um corpo de imagens que nos dão razões ou ilusões de estabilidade. Uma porta, um calçado, uma parede, um bordado, uma gaveta foram potencializados, ganharam sentidos novos, narrativas implicadas com o fazer.

A representação desses espaços íntimos trouxe ainda outros elementos, relacionados diretamente ao perfil social de estudantes participantes. Os registros que emergiram como parte de produtos do curso - exercícios, diálogos, depoimentos, projetos finais - representam a leitura da realidade de uma maioria de estudantes mulheres jovens, negras e de baixa renda que chegaram à universidade pública e que de repente tiveram essa experiência cotidiana - e tudo o que ela representa - interrompida. Com a pandemia, o convívio com o espaço físico universitário e as trocas que ele proporciona fora substituído pela presença da universidade - ou uma porção dela - dentro de casa. Ou seja, já não era possível ir ao locus, por excelência, do conhecimento formal. Ao invés disso seria necessário incorporar a dimensão possível da universidade ao caos de cada um/uma, de cada vida em sua porção mais íntima. Isso inclui não só limitações nas condições gerais de acesso à Internet, mas a constituição de cada espaço familiar em sua dimensão física - o quarto, a sala, a casa - e em sua dimensão social - quem habita.

Com isso, estávamos diante não mais de estudantes tal como conhecíamos no ambiente universitário, mas de sujeitos imersos em seus contextos de origem. Nós, professoras e professor, nesta mesma condição. De nossas casas, com algo de nossa intimidade exposto e, especialmente naquele momento, algo de nossas fragilidades. Para além de uma atividade acadêmica, a experiência do MostreEmCasa foi, portanto, formativa no sentido de enxergarmos estudantes participantes em perspectiva que não conseguiríamos captar em sala de aula e de, a partir desta experiência, refletirmos sobre a nossa condição de educadores.

Naquele momento de medos e incertezas, MostrEmCasa dava a impressão de nos manter em ligação por uma rede de apoio e trabalho colaborativo, mesmo que no começo, como ideia e como processo aberto, não pudesse nos dar essa garantia. Como uma casa, o nosso fazer lançado num mundo e num tempo tão difíceis, aquela experiência se tornou, pouco a pouco, abrigo temporário para compartilhamento das incertezas, medos e expectativas sobre o futuro. O corpo presente, sentindo, vibrando, envolvido, incorporado no coletivo e enredado nas tramas do possível com a arte e as tecnologias, construindo novas consciências de si, (re)existindo.

\section{AGRADECIMENTOS}

Este trabalho também é resultado de discussões coletivas no Grupo de Pesquisa INTERFACES da Universidade do Estado da Bahia-UNEB, no sentido de refletir a práxis formativa no curso de Relações Públicas, considerando a pauta contemporânea de enfrentamento às questões de diversidade, diferenças, desigualdades e direitos de minorias subalternizadas e invisibilizadas.

\section{REFERÊNCIAS}

Akotirene, Carla. 2019. O Que é Interseccionalidade? Coleção Fe. São Paulo, Brasil: Sueli 
Carneiro; Pólen.

Bachelard, Gaston. 2000. A Poética Do Espaço. Sao Paulo - Brasil: Martins Fontes.

Barbier, René. 1998. “A Escuta Sensível Na Abordagem Transversal.” In

Multirreferencialidade Nas Ciências e Na Educação, edited by Joaquim Barbosa. São

Carlos, SP-Brasil: Editora da UFSCar.

Beck, Ulrich, Anthony Giddens, and Scott Lasch. 1995. Modernização Reflexiva:

Política, Tradição e Estética Na Ordem Social Moderna. São Paulo, Brasil: UNESP.

Bronowski, Jacob. 1983. Arte e Conhecimento: Ver, Imaginar, Criar. Lisboa, Portugal: Edições 70.

Burke, Peter. 2003. Uma História Social Do Conhecimento: De Gutemberg à Diderot. Rio de Janeiro, Brasil: Jorge Zahar.

Escobar, Arturo. 2005. Más Allá Del Tercer Mundo. Globalización y Diferencia. Bogotá, Colombia: Instituto Colombiano de Antropologia e História-Universidad del Cauca.

Fidalgo, António. 2020. “Ensino de Corpo e Alma.” Jornal Observador, 2020.

Fróes Burnham, Teresinha. 2000. Sociedade Da Informação, Sociedade Do

Conhecimento, Sociedade Da Aprendizagem: Implicações Ético-Políticas No Limiar Do

Século. Edited by Lídia Lubisco, Nídia; Brandão. Informação. Salvador - Brasil: EDUFBa.

Gadamer, Hans-Gerg. 1997. Verdade e Método. 2nd ed. Petrópolis, RJ Brasil: Vozes.

Jenkins, Henry. 2008. Cultura Da Convergência. Trad. Susa. São Paulo, Brasil: Aleph.

Lander, Edgardo. 2005. "Ciências Sociais: Saberes Coloniais e Eurocêntricos.” In A

Colonialidade Do Saber: Eurocentrismo e Ciências Sociais. Perspectivas

Latinoamericanas, 08-23. Ciudad Autónoma de Buenos Aires, AR: CLACSO.

Lash, Scott. 2005. Crítica de La Información. 1st ed. Buenos Aires, AR: Amorrortu.

Lévy, Pierre. 1999. Cibercultura. Edited by Carlos Irineu da Costa. São Paulo, Brasil: Editora 34.

Marotta, Vince. 2017. "The Cyborg Stranger and Posthumanism." In Theories of the Strange: Debates on Cosmopolitanism, Identity and Cross-Cultural Encounters, 1st ed. New York: Routledge Taylor \& Francis Group.

Mattos, Wilson Roberto de. 2007. Contribuição Historiográfica Ao Debate Sobre Ações Afirmativas: Exclusão Racial Na Bahia Do Século XIX. Salvador - Brasil: EDUFBa.

Meneses, Maria Paula, and Boaventura de Sousa Santos. 2009. Epistemologias Do Sul. Revista Crítica de Ciências Sociais. Coimbra, Portugal: Edições Almedina SA. https://doi.org/10.4000/rccs.689.

Morin, Edgar. 1993. "Edgar Morin, Contrabandista Dos Saberes." In Do Caos à Inteligência Artificial: Quando Os Cientistas Se Interrogam, edited by Guitta PessisPasternak, 83-94. Sao Paulo - Brasil: Editora da Universidade Estadual Paulista. 
OCDE. 2020. "The Impact of COVID-19 on Education: Insights from Educations at a Glance 2020." OCDE. 2020.

OMS. 2020. "WHO Director-General's Opening Remarks at the Media Briefing on COVID-19." OMS. 2020.

Pareyson, Luigi. 2001. Os Problemas Da Estética. 3a ed. São Paulo, Brasil: Martins Fontes.

Queiroz, Delcele Mascarenhas. 2000. "Desigualdades Raciais No Ensino Superior: A Cor Da UFBA." In Educação, Racismo e Anti-Racismo. Programa "A Cor Da Bahia" UFBA, edited by Delcele Mascarenhas et al Queiroz, 11-44. Salvador - Brasil: UFBA.

Queiroz, Delcele Mascarenhas. 2002. "Desigualdades Raciais No Ensino Superior No Brasil." In O Negro Na Universidade. Programa "A Cor Da Bahia - UFBA, edited by Delcele Mascarenhas et al Queiroz, 13-55. Salvador - Brasil: UFBA.

Ribeiro, Renato Janine. 2020. "Educação Na Pandemia e Volta Às Aulas: Ex-Ministro Renato Janine Ribeiro Conversa Com Paulo Makun.” 2020.

Ribeiro, Renato Janine. 2021. "Ex-Ministro Da Educação Critica: Brasil é Um País Apaixonado Pela Abstração.” Revista Ensino Superior. 2021.

Rubino, Silvana, and Marina Grinover. 2009. Lina Por Escrito. Sao Paulo - Brasil: Cosac Nayfy.

Santos, Boaventura de Sousa. 2001. Pela Mão de Alice: O Social e o Político Na PósModernidade. 8a ed. Sao Paulo - Brasil: Cortez.

Santos, Boaventura de Sousa. 2020. A Cruel Pedagogia Do Vírus. Coimbra, Portugal: Edições Almedina SA.

UNICEF, WHO, and IFRC. 2020. "Key Messages and Actions for COVID-19 Prevention and Control Is Schools." 2020.

Vicini, Andrea, and Agnes M. Brazal. 2015. "Longing for Transcendence: Cyborgs and Trans- and Posthumans." Theological Studies 76 (1): 148-65.

https://doi.org/10.1177/0040563914565308.

Wertheim, Margaret. 2001. Uma História Do Espaço de Dante Aà Internet. Rio de Janeiro, Brasil: Jorge Zahar. 